\title{
FUNÇÃO DE DRENAGEM PURIFICADORA DO SISTEMA NERVOSO CENTRAL PELO LIQUIDO CEFALORRAQUIANO
}

\author{
JOAOO BAPTISTA DOS REIS-FILHO *
}

A absorção pelo líquido cefalorraquiano (LCR) de produtos derivados do metabolismo é uma concepção antiga baseada na suposição dele exercer para o sistema nervoso central (SNC) a mesma função que a linfa em outras partes do organismo. Mestrezat ${ }^{5}$, em seu tratado sobre LCR publicado no ano de 1912, fez uma revisão crítica da opinião dos autores, alguns admitindo ser o LCR a própria linfa do SNC, enquanto outros julgavam essa hipótese pouco provável. Em sua argumentação ele fez considerações muito precisas sobre 0 assunto para essa época.

Não há vias linfáticas no tecido nervoso; não há conexão direta dos espaços pericelulares com as bainhas perivasculares, as quais vão se abrir nos espaços subaracnóideos. O LCR tem concentração reduzida de proteínas e pobreza em elementos celulares o que não é compatível com a sua poluição forçada por uma linfa procedente das bainhas perivasculares. Sendo fundamentalmente um líquido mineral, que contém componentes orgânicoss em muito pequena concentração, o LCR não constituiria um meio linfático, não tendo condições para exercer função nutritiva. Por outro lado, o LCR não poderia ser a linfa do SNC porque, recebendo e eliminando produtos de seu metabolismo, não seria o meio interno ideal, como ele o é. A explicação então sugerida foi admitir que na intimidade do tecido nervoso, ao nível arterial do capilar, haveria transudação de serosidade para os espaços extracelulares e, depois de desempenhada sua função, esta serosidade seria reabsorvida no lado venoso do capilar. Não haveria pois uma mistura de uma linfa do SNC com o LCR, evitando-se assim a sua poluição, conforme concluiu Mestrezat ${ }^{5}$.

Estes fatos convenceram a maioria dos autores que não existe uma verdadeira circulação linfática no SNC.

Entretanto, Davson e col. 1, em uma primeira investigação, mostraram evidências que sugeriam a perda de substâncias introduzidas no LCR, que possivelmente poderiam indicar uma função de eliminação purificadora para o tecido nervoso, em determinadas condições experimental ou patológica. Em prosseguimento, com o caráter introdutório para este assunto, estão resumidas as considerações gerais de Davson ${ }^{2}$ sobre a constituição do líquido extracelular e sobre o sistema linfático.

Departamento de Neurologia e Neurocirurgia, Escola Paulista de Medicina: *Professor Adjunto. 
Admite-se que o líquido extracelular em outras partes do organismo, como exemplo nos músculos, é um filtrado do plasma sanguíneo. A filtração processa-se em decorrência da pressão hidrostática que é relativamente elevada no capilar arteriail, enquanto que é muito menor no capilar venoso. Aqui, devido à maior força osmótica intracapilar ocorre, numa segunda fase, a absorção do líquido extracelular. Este estado dinâmico determina uma movimentação programada do líquido extracelular, com formação na extremidade arterial e absorção no capilar venoso. Quando surge produção excessiva que perturba este equilibrio dinâmico, o sistema linfático entra em ação. A composição química deste líquido extracelular pode ser conhecida com antecipação, pois é um filtrado de plasma com suas modificações devidas an metabolismo ou outros fatores. $\mathrm{O}$ filtrado não é perfeito e porisso existe uma taxa de proteinas relativamente elevada. Se esta concentração das proteínas aumentar muito, a semelhança relativa das pressões oncóticas do líquido extracelular e do plasma vai dificultar a sua absorção ao nível do capilar venoso, de sorte que resulta a formação de edema. Entretanto, em condições normais, por meio da elevada permeabilidade de suas paredes, os capilares linfáticos mantêm a concentração das proteínas dentro de limites razoáveis, promovendo a sua remoção e a de outros componentes do líquido extracelular, por difusão. Como os grandes vasos linfáticos têm válvulas, resulta um fluxo de retorno do líquido extracelular para o sangue venoso (Figura 1).

Em relação ao SNC, o mecanismo de manutenção de um ambiente propício às células do parênquima é inteiramente diferente, visto como não há sistema linfático no tecido nervoso. Assim, a passagem de proteínas do plasma para o espaço extracelular poderia ser evitada por uma ou ambas destas duas formas:

1 - Capilares com permeabilidade reduzida, isto é, a barreira hematencefálica; 2- LCR como um sistema de drenagem, atuando como linfático do SNC.

Uma barreira altamente seletiva entre sangue e líquido extracelular poderia ser atribuída em primeiro lugar à formação de junções impermeáveis entre todas as células endoteliais dos capilares, representando por assim dizer a "sede da barreira". De outro lado, ou alternativamente, a restrição à permeabilidade poderia ser conseguida por meio do revestimento das células endoteliais pelos processos dos astrócitos, que proporcionariam as junções compactas lateralmente. A presença de uma membrana altamente seletiva, somente lentamente permeável, e mesmo isto ocorrendo exclusivamente para solutos do plasma de pequeno peso molecular, evidentemente impediente para proteínas, seria importante para evitar ou reduzir a possibilidade de edema a uma incidência desprezível e, com outra vantagem adicional, que é a de dificultar a passagem de moléculas indesejáveis do sangue para os neurônios. Muitas substâncias, presentes no sangue para desempenhar uma função útil, quando passam para o LCR podem exercer um efeito prejudicial. Como exemplo, a adrenalina, acetilcolina, histamina, com seus efeitos benéficos quando na corrente sanguínea, são nocivos quando no LCR. Além disto a barreira protege os neurônios das variaçōes sanguíneas amplas e súbitas dos ions $\mathrm{K}^{+}, \mathrm{Ca}^{++}$e $\mathrm{Mg}{ }^{++}$, que afetariam criticamente e excitabilidade dos neurônios e suas sinapses. 

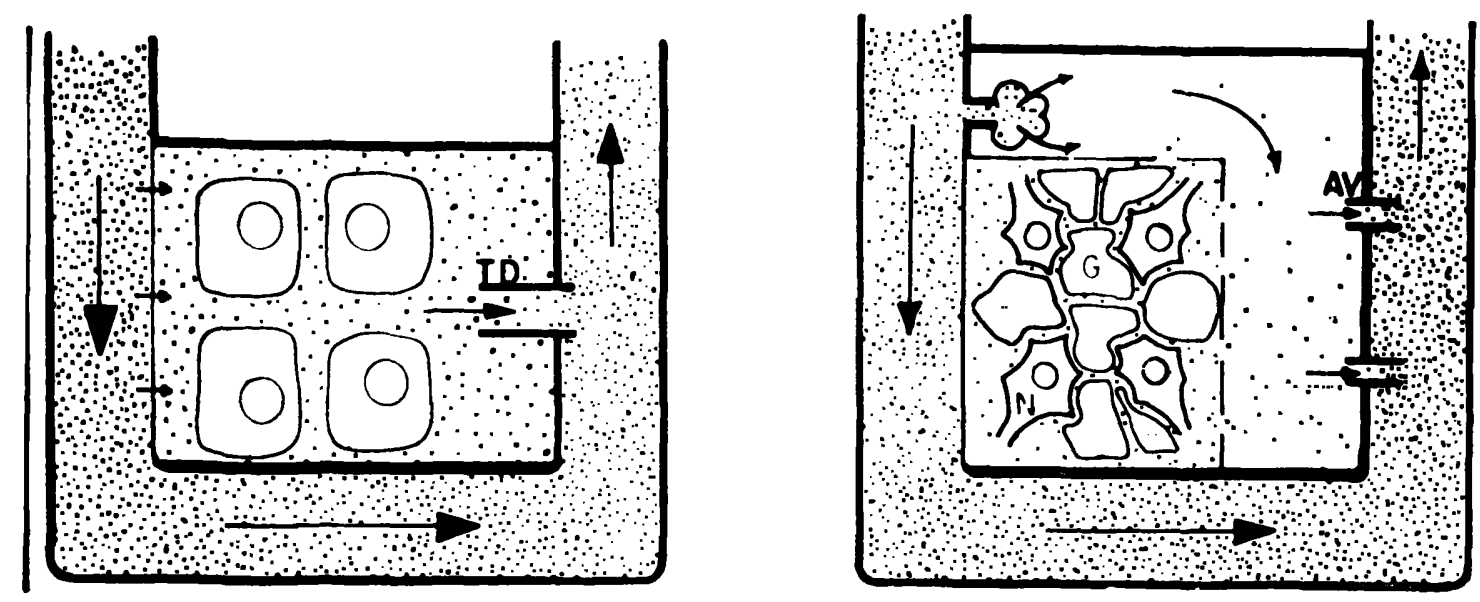

Figura 1 - Esquerda, diagrama do circuito do líquido extracelular, mostrando o fluxo ativo da linfa para os dutos convergentes, e finalmente para o sangue venoso atraves do duto tordxico (TD). A linfa tem um fluxo, nos dutos, suficiente para impedir o retorno, por difusão, de substancias com maior concentraça no sangue. O fluido extracelular aqui difere muito pouco da composição química do plasma. Direita, diagrama indicando a relacão entre - plasma sanguineo, o compartimento do tecido cerebral com as células gliais (G), preenchendo os espacos entre neuronios (N), e o LCR que tira solutos do espaço extracelular por difusão e finalmente retornando para o sangue venoso. Neste diagrama a vilosidade da aracnóide (AV) pode ser vista como análoga ao duto toraxico. A modificação do mecanismo, de drenagem do espaco extracelular, visto em outros óngãos, permitivia a remocão, do espaco extracelular cerebral, de solutos incapazes de retornarem por difusão ao sangue, enquanto se mantém o fluxo do fluido extracelular em um minimo. Este fluxo lento permitiria um controle mais efetivo da composição eletrolitica. Tanto a esquerda como a direita as linhas fortes representam compartimentos impermedveis $e$ as linhas finas indicam superficies através das quais pode haver alguma forma de transferencia. Reprodução de esquemas de Oldendorf \& Davson 6.

As principais partes das paredes ventriculares 7 estão revestidas por células ependimárias que se apresentam recobertas por densa camada de cílios e nestas regiões as junções celulares são frouxas, em contraste com o que acontece em algumas regiões especializadas, tais como as áreas dos plexos corióideos e outras bem definidas, conhecidas com a denominação de áreas em relação com os órgãos circunventriculares, onde as células estão isentas de cílios e apresentam junções compactas. Um sistema de drenagem do tecido nervoso funcionaria por intermédio dos revestimentos ependimário e/ou glial, que são bastante permeáveis às proteínas e outros constituintes de molécula grande, permitindo as suas saídas do tecido nervoso, isto é, um vazamento destas substâncias para o LCR e depois daqui para o sangue, por um mecanismo valvular. Poderia ser estendida esta afirmação para admitir-se a finalidade de depurar o sistema nervoso de substâncias estranhas ou normais em teor aumentado que poderiam perturbar a sua função. Por este mecanismo de eliminação ou transporte o LCR receberia do tecido nervoso, através das membranas de seu revestimento, a ependimária $\mathrm{e}$ a pia-glial, certos componentes procedentes do plasma sanguíneo e os encaninharia para a sua reabsorção ao nível das vilosidades da aracnóide. Desta forma, o LCR poderia recolher, desde os ventrículos até os espaços subaracnóideos, um progressivo contingente de elementos procedentes do espaço extracelular do SNC, mantendo-os dentro de certos limites pelo processo de 
eliminação ao nivel das vilosidades da aracnóide. Deve-se anotar a peculiaridade de que nenhum ponto do encéfalo humano dista mais que $2 \mathrm{~cm}$ das superfícies ependimária ou pioglial, em geral $1 \mathrm{~cm}$, e a maior parte da substância cinzenta está a apenas a alguns milímetros de distância. Esta disposição pode indicar as condições para as quais a transferência por difusão é efetiva, isto é, favorece a drenagem depuradora (Figura 2).

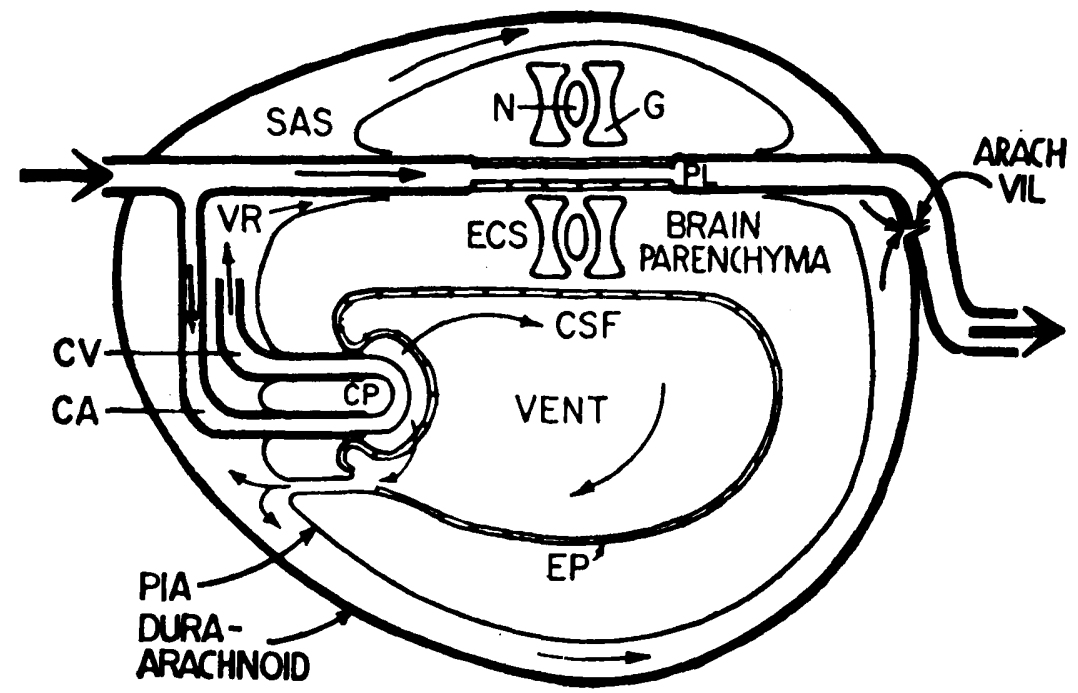

Frigura 2 - Diagrama representando as relaçoses entre o espaco extracelular $e$ tecido cerebral: $G=$ glia; $N=$ neuronio; $P L=$ plasma sanguimeo; $\$ A S=$ espago subaracnoideo; VENT = ventriculo; $E P$ $=$ ependima; $C P=$ plexos corioides; $C A=a r-$ téria corioidea; $C \bar{V}=$ veia corioidea; $A R A C H$ $V I L=$ vilosidades $d a$ aracnbide; $V R=$ espaco de Virchow-Robin. Reproducão de esquemas de Oldendorf \& Davson 6.

A fim de demonstrar ser esta hipótese verdadeira, Oldendorf em colaboração com Davson executou uma investigação bem programada, procurando evidências de que realmente o LCR exerce uma função de drenagem de um indicador marcado introduzido na corrente sanguinea ${ }^{6}$. Esta pesquisa teve por finalidade evidenciar o vazamento de um marcador do espaço extracelular, saindo do tecido nervoso (encéfalo) e dirigindo-se para o LCR. Foram feitas três medidas da quantidade de distribuição do marcador do espaço extracelular, sacarose sinalizada com $\mathrm{C}^{14}$, a primeira mantendo constante o seu nível no plasma sanguíneo e determinando a sua concentração no encéfalo, ao mesmo tempo em que se fazia a perfusão dos ventrículos com LCR artificial; a segunda, mantendo um nível constante do marcador no LCR artificial, que era perfundido através dos ventrículos, e determinando a sua concentração no encéfalo, em diversos períodos; a terceira, mantendo o marcador em níveis constantes e aproximadamente semelhantes no plasma sanguíneo e no LCR perfundido através dos ventrículos, e determinando-se as concentrações do indicador no encéfalo em diversos periodos. As duas primeiras condições experimentais permitem o vazamento do indicador, na primeira para o LCR artificial de perfusão ventricular, na segunda experiência torna possivel a passagem para o sangue, encéfalo e plexos corióideos; finalmente, na condição experimental terceira, a saída do marcador é evitada, por motivo de estar impossibilitado o seu escoamento para o sangue 
ou LCR. Os resultados destas três condições experimentais permitiram a comprovação da hipótese do vazamento, postulada por Davson 1.

Oldendorf e Davson 6, baseados em suas investigações sobre a função de depuração do SNC pelo LCR, fizeram considerações muito sensatas sobre diversos problemas ainda não resolvidos em relação com a fisiologia do $L C R$, tais como o mecanismo de origem do gradiente protéico ventrículo-lombar, o mecanismo de proteção do SNC contra substâncias circulantes no sangue que afetariam a sua função e o mecanismo homeostático de regulação da concentração de íons dentro de limites estreitos, para a proteção de centros de importância fisiológica vital.

O LCR, no momento de sua produção pelos plexos corióideos, é quase isento de proteinas. Ele movimenta-se dentro do sistema ventricular e entra, na base do crânio, nos espaços subaracnóideos da região espinhal e da convexidade do encéfalo, antes de alcançar as vilosidades da aracnóide. Nesta sua movimentação, as proteínas procedentes das paredes dos capilares são recebidas no espaço extracelular e daqui, por difusão, penetram no LCR progressivamente, resultando daí um gradiente de concentração. Neste seu deslocamento ventrículo-subaracnóideo a quantidade de proteinas cresce continuadamente, atingindo até quase o nível de 1 por cento de sua concentração no plasma, em condições normais.

Os capilares do encéfalo são relativamente impermeáveis às proteínas. Não se sabe ao certo qual o motivo determinante desta vedação, mas pode ser devida a um mecanismo de proteção, para afastar diversas substâncias neurotóxicas existentes no sangue que estão ligadas às proteínas do plasma, como por exemplo a bilirrubina. Este é apenas um exemplo do controle rígido da composição do líquido extracelular do encéfalo.

O LCR apresenta em relação a alguns componentes constituição aproximadamente semelhante à do líquido do espaço extracelular, porém diferente em relação a outros, como por exemplo $\mathrm{Na}^{+}, \mathrm{Cl}-, \mathrm{Mg}^{++}$que estão em maior concentração no LCR que no filtrado de plasma e $\mathrm{K}^{+}$, uréia e glicose em menor concentração. Por um mecanismo homeostático o LCR mantém constante a sua composição, apesar das grandes alterações de componentes plasmáticos.

E muito provável que estes três mecanismos descritos acima estejam em relação com a função de drenagem purificadora do LCR sobre o líquido do espaço extracelular do SNC. Além disto os resultados das pesquisas de Hochwald e col. ${ }^{4}$ indicam que o conceito de uma ação de eliminação pelo LCR pode também ser admitido para explicar o mecanismo da drenagem da água acumulada no tecido nervoso durante a intoxicação hídrica. Fishman ${ }^{3}$, apoiando-se neste trabalho, considera possível este mesmo processo de recuperação funcional do SNC em outros tipos de edema, além daquele da intoxicação aquosa.

RESUMO

Por motivo da ausência de um sistema linfático no encéfalo, o produto derivado de seu metabolismo somente pode ser removido por duas vias, pelo fluxo sanguíneo capilar ou pela sua transferência ao LCR. Davson havia sugerido que esta segunda forma seria possível, o LCR exercendo uma função de 
eliminação depuradora para o tecido nervoso e, posteriormente, juntamente com Oldendorf, demonstrou experimentalmente ser esta hipótese admissível. De acordo com esta concepção, o produto do metabolismo encefálico não aproveitável se difundiria em condições normais para o LCR e daqui seria removido pelo mecanismo habitual de sua reabsorção. Da mesma forma, qualquer soluto que atravessasse a barreira hematencefálica em proporção prejudicial seria desviado do tecido nervoso, evitando-se que sua concentração mais elevada perturbasse a função cerebral. Por meio da sua reabsorção nas vilosidades da aracnóide, o LCR eliminaria lentamente este soluto que passou do sangue para - SNC. De modo semelhante, a água em excesso poderia ser removida do tecido nervoso em pacientes com edema encefálico.

\section{SUMMARY}

\section{Sink action of cerebrospinal fluid.}

It has long been known that the cerebrospinal fluid can not be the nervous system lymph, and Mestrezat, in his authoritative book of the year 1912, demonstrated it plainly. Davson has undertaken this subject and suggested the hypothesis of a sink action of cerebrospinal fluid, allowing a slow leakage of solutes from nervous tissue extracellular space. In order to test this hypothesis, Oldendorf and Davson performed a series of animal experiments and they demonstrated that there was leakage of the solute into cerebrospinal fluid. Based on the idea of this sink action of cerebrospinal fluid, some possible physiological implications were considered such as the mechanism of origin of the ventricle-subarachnoid cerebrospinal fluid protein gradient; the mechanism of protection of the central nervous system against the harmful substances of the blood stream; and the homeostatic mechanism whereby the concentration of some ions of the fluid remains constant. Also, it is considered the possibility of a sink action of cerebrospinal fluid in the resolution of brain edema in water intoxication and other types of central nervous system edema.

\section{REFERENCIAS}

1. DAVSON, H.; KLFEMAN, C. R. \& LEVIN, E. - Quantitative studies of the passage of different substances out of the cerebrospinal fluid. J. Physiol. 161:126, 1962.

2. DAVSON, H. - Physiology of the Cerebrospinal Fluid. Churchill, London, 1967.

3. FISHMAN, R. A. - Cerebrospinal Fluid in Diseases of the Central Nervous System. Saunders, Philadelphia, 1980.

4. HOCHWALD, G. M.; WALD, A. \& MALHAN, C. - The sink action of cerebrospinal fluid volume flow. Effect on brain water content. Arch. Neurol. 33:339, 1976.

5. MeStREZAT, W. - Le Liquide Céphalo-rachidien Normal et Pathologique. A. Maloine, Paris, 1912.

6. OLDENDORF, W. H. \& DAVSON, H. - Brain extracellular space and the sink-action of cerebrospinal fluid. Arch. Neurol. 17:196, 1967.

7. WEINDL, A. \& JOY.NT, R. J. - Ultrastructure of the ventricular walls. Three dimensional study of regional specialization. Arch. Neurol. 26:420, 1972. 